\title{
Desain dan Implementasi Program E-Learning Berbasiskan ICT
}

\author{
Afrizal Mayub*, Rendy Wikrama Wardana \\ S2 Pendidikan IPA, Universitas Bengkulu, Jl.Raya kandang Limun No.1 Bengkulu, Indonesia \\ *Email: afrizalmayub@unib.ac.id
}

DOI: $\underline{\text { https://doi.org/10.33369/pendipa.6.1.256-262 }}$

\begin{abstract}
[ICT-Based E-Learning Program Design and Implementation]. This paper describes the Design and Implementation of ICT-based E-learning programs that can be used for learning either through computer networks or personal computers (PCs) with CD ROMs. This research includes software engineering with methods of analysis, design, coding and evaluation. Based on the results of the study, it was obtained that the Design and Implementation of E-learning Program consisted of modules of material presentation, demo, analysis, examination, Practice test, Problem Answer and Help Module. The module can function as a learning tool that facilitates learning needs for learning activities that include reading, staring, watching, peeping, observing, simulating, demonstrating, answering questions, entering data, listening, tracing teaching materials, working on problems, and finding answers to problems.
\end{abstract}

Keywords: Design, Implementation, e-learning program.

\begin{abstract}
ABSTRAK
Artikel ini memaparkan Desain dan Implementasi Program E-learning berbasiskan ICT yang dapat digunakan untuk pembelajaran baik melalui jaringan komputer maupun komputer pribadi (PC) dengan CD ROM. Penelitian ini termasuk produk software engineering dengan metode analisis, desain, pengkodean dan evaluasi. Berdasar hasil penelitian diperoleh Desain dan Implementasi Program Elearning yang terdiri atas modul sajian materi, demo, analisis, examination, practice test, jawaban pasalah dan modul bantuan. modul tersebut berfungsi sebagai sarana belajar yang memfasilitasi kebutuhan belajar untuk kegiatan belajar yang mencakup membaca, menatap, mengawasi, mengintip, mengamati, mensimulasikan, mendemokan, menjawab pertanyaan, memasukkan data, mendengarkan, menelusuri materi ajar, mengerjakan soal, dan mencari jawaban permasalahan. Interaksi edukatif user dengan Program e-learning dapat bekarja dengan sangat baik.
\end{abstract}

Kata Kunci: Desain, Implementasi, Program e-learning.

\section{PENDAHULUAN}

Penerapan Teknologi informasi dalam bidang pendidikan berupa sekolah maya dapat dikatakan sebagai bentuk e-leraning (Purbo., et al, 2002). Pendidikan berbasis ICT merupakan pendidikan yang pembelajarannya berlangsung dengan memanfaatkan teknologi informasi, merupakan suatu E-learning (Putra, D; 2009). Pendapat lain mengatakan e-learning adalah pembelajaran yang dilakukan melalui media elektronik, seperti Internet, Intranet, Ektranet, CDROM, video tape, DVD, TV, Handphone, PDA dll (Team e-learning, 2004). E-Learning berbasis CD-ROM, memungkinkan materi pembelajaran dapat dibawa mahasiswa dalam bentuk CD-ROM, kemudian dipelajari pada komputer. Sejalan dengan hal itu, peran ICT yang mencakup segala aspek kehidupan sangat dominan. Peran dan kemampuan ICT dapat digunakan untuk membuat program pembelajaran yang berfungsi sebagai wadah Pembelajaran bagi siswa.

Kemampuan komputer sebagai sarana pembelajaran (e-learning) dimungkinkan dibuat wadah pembelajaran yang bersifat multimedia interaktif, sehingga pengguna sarana pembelajaran dapat bersifat aktif, selain bersifat reaktif atau pasif. Komputer juga memungkinkan adanya individualisasi dalam belajar karena materi ajar dan latihan dapat disusun sesuai dengan model perkembangan kecerdasan pengguna. E-learning berbais ICT harus mampu untuk "meng-konkretkan" konsep yang abstrak sehingga mudah dimengerti oleh siswa, hal ini dapat diwujudkan dengan bantuan komputer.

Peneliti di Turki menemukan bahwa, 
sebagian kecerdasan dapat dilacak dan difasilitasi melalui analisis pembelajaran multimodal dalam mode online, karena mode ini berkemampuan untuk mendukung multi-literasi. Mode ini dibantu dengan teknologi Informasi dan mengadaptasi teori pendidikan dapat digunakan untuk pelatihan guru online (Ayesha P, 2018). Di afrika selatan, potensi siswa dapat dimaksimalkan dengan pembelajaran berbasis kecerdasan ganda (FE Gouws, 2008). Siswa yang belajar di mode offline ataupun di mode on-line melalui pembelajaran adaptif dan sistem E-Learning Cerdas Adaptif menemukan, hasil belajar siswa akurat sebesar 85\% (Bhaskaran at, al 2014).

Semua kecerdasan dapat tumbuh dan berkembang optimal bila didukung oleh Program e-Learning (Pappas. C, 2005). Untuk meminimalkan tingkat dropout dari kursus pembelajaran jarak jauh dan untuk mempromosikan keberhasilan siswa secara keseluruhan di sekolah dan Perguran Tinggi dapat digunakan model elearning (DeGennaro, 2010). Riset lain mengatakan bahwa, Untuk menyediakan opsi yang lebih menarik dalam belajar dapat diimplementasikan dengan pendekatan Virtual Classroom mampu (Marie, 2009). Proses belajar menjadi efektif bila menggunakan potensi yang dimiliki Virtual Learning (Haryono, 2012). Demikian pula riset di Waseda Jepang, menemukan bahwa, terdapat perbedaan signifikan antara pembelajaran menggunakan e-learning dengan pembelajaran secara tradisional dan e-learning merupakan pembelajaran yang efektif, (Laela Halawi dkk, 2010).

Agar siswa belajar secara leluasa, mandiri, mudah memahami yang abstrak, dan dapat melakukan praktikum secara virtual dapat difasilitasi melalui Pembelajaran e-learning (Mustadji., 2011). Pembelajaran Fisika, bila dikemas dengan animasi yang baik dan benar menjadi enak dikomsumsi mahasisawa (DePorter and Hernacki., 2011). Pembelajaran bermakna, pengelolaan pembelajaran efisien, administrasi siswa lebih efektif dapat difasilitasi dengan Penggunaan komputer (Morten Brekke, Per Henrik Hogstad., 2010). Dosen yang mempunyai keterbatasan kemampuan dalam mengelola pembelajaran dapat dibantu dengan memanfaatkan sarana pembelajaran berbasis ICT (Nawaz, 2011). Web yang memuat halaman muka, pendahuluan, dan halaman course yang terdiri atas course 1 memuat peta kompetensi dan peta konsep serta 3 corse lainnya berisi tujuan, materi ajar, eksperimen, diskusi, tokoh sains, rangkuman dan materi ujian yang memanfaatkan menu resource dan activity baik dilakukan dalam Pembelajaran IPA dapat diwujudkan melalui Media Pembelajaran IPA Terpadu Interaktif (Miftah R.S, et al, 2012). Jika didukung oleh sarana dan prasarana jaringan, serta sosialisai metodenya, maka Metode Pembelajaran Berbasis E-learning tersebut pada civitas akademika di Direktorat Program Diploma IPB dapat dilaksanakan dengan baik (Budi, et al, 2012). Untuk meningkatkan proses belajar-mengajar pada SMA N 10 Bandar Lampung dengan baik dapat dilakukan melaui system e-learning Learning Management System yang menggunakan analisa ANP (Hidayati, 2010).

Berdasar uraian di atas masalahnya dapat dirumuskan sebagai berikut; "Bagaimakah Desain dan Implementasi program pembelajaran e-learning berbasis ICT dapat diwujudkan". Untuk menjawab permasalahan di atas perlu ditetapkan tujuan penelitian yaitu; untuk mewujudkan Implementasi program pembelajaran e-learning berbasis ICT dan mendiskripsikan model Desain program elearning.

\section{METODE PENELITIAN}

Penelitian ini termasuk jenis Penelitian Pengembangan atau Research and Developmen. Bagian ini akan menguraikan proses dari pembuatan Program Pembelajaran berbasiskan ICT sampai kepada uji Program Pembelajaran tersebut. Proses pembuatan Program Pembelajaran meliputi: Analysis, Design, Code, dan Testing (Mayub, A., 2011).

\section{Analisis}

Analisis kebutuhan program e-learning merupakan analisis kebutuhan terhadap software, hardware, dan sumber daya manusia yang diperlukan untuk terwujudnya program $e$ learning. Dalam tulisan ini diperlukan software macromedia flash, satu set komputer/laptop, 1 orang yang mengerti fisika serta 1 orang programer.

\section{Desain}

Merencanakan program e-learning dari awal sampai akhir, untuk itu perlu ditetapkan; topik yang akan dibuat, model animasi yang akan digunakan, materi yang akan ditampilkan, jenisjenis demo yang akan dibuat, alur informasi sistem yang akan dibuat secara prosedural, struktural, dan tampilan, evaluasi desain-desain yang telah dibuat, revisi bila ditemukan masalah, serta memutuskan software apa yang akan digunakan. Adapun pekerjaan desain ini meliputi 
desain modul sajian materi, demo, analisis, examination, practice test, jawaban masalah dan modul bantuan.

\section{Menulis Program.}

Program dibuat mengunakan pemrograman ActionScript, dengan tahapan, buka macromedia flash $M X$, Buat objek yang akan dijadikan bagian movie, Buat button yang diperlukan, pilih objek untuk dijadikan instance dengan arrow tool, Sorot menu insert dan klik create motion tween, Sorot window pilih panel dan klik intance, Pilih movie klip dan buat nama dan sorot window dan klik action, pilih expert mode, dan sorot action dan klik 2x salah satu menu, tulis program, dan lakukan test movie. Untuk menguji interaktivitas sistem dengan pengguna, gunakan button yang telah dibuat, dan lakukan penilaian tentang kesesuaian hasil dengan rencana yang telah ditetapkan. Sekiranya hasil uji belum memuaskan lakukan revisi seperlunya, selanjutnya dilakukan pengujian sampai diperoleh hasil sesuai rencana.

\section{Uji coba Program e-learning}

Uji coba dilakukan untuk membuktikan bahwa program e-learning yang telah dibuat benar terbukti dapat dioperasikan dan digunakan untuk proses pembelajaran fisika. Tujuan pengujian adalah untuk memastikan program berjalan sesuai dengan yang direncanakan, semua button dapat berfungsi untuk interaktivitas, hasil eksekusi program sesuai dengan konsep ilmu fisika, tampilan yang dihasilkan dalam katagori layak, dan waktu tanggapnya. Pengujian dilakukan dengan cara play, dan test movie. menguji, apakah tampilan hasil eksekusi program sesuai dengan minat dan motivasi user, untuk itu perlu tahap-tahap pembuatan seperti Gambar 1.

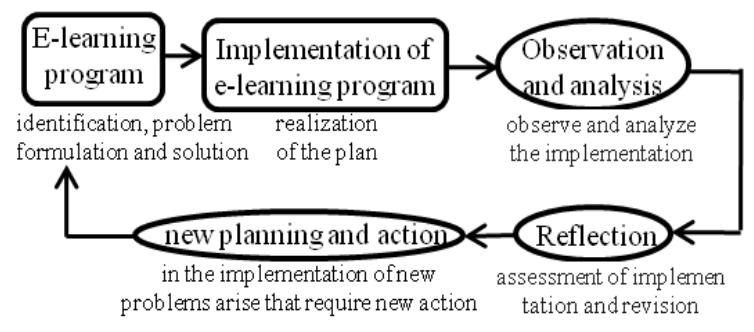

Gambar 1. Tahapan Program E-Learning

\section{Implementasi Program e-learning}

Implementasi Program e-learning meliputi modul modul berikut

Modul Materi ajar, Modul ini memuat informasi tentang materi fisika dasar Gerak Dua Dimensi yang meliputi; Gerak Parabola, Gerak
Satelit, dan Gerak Roket. Untuk interaktivitas sistem dengan siswa digunakan button-button. Sajian materi dilengkapi dengan masalah, yang berfungsi untuk mengajak siswa berdialog secara maya, disediakan juga jawaban dari masalah.

Modul Demo, Modul ini memuat program demo tentang materi fisika yang dibahas. Untuk interaktivitas sistem dengan siswa digunakan button-button. Siswa dapat memasukkan input pada tempat yang telah disediakan, sehingga ada interaktivitas dengan user secara bebas terbatas.

Modul Analisis, Modul ini memuat program analisis secara kuantitatif berupa angka hasil perhitungan terhadap soal/ masalah yang disajikan, dilengkapi juga dengan demo yang diperlukan. Interaktivitas sistem-siswa menggunakan button

Modul Examination, Modul examination merupakan modul yang berfungsi untuk menguji kemapuan siswa terhadap satu pokok bahasan / topik pelajaran tertentu, misalnya gerak dua dimensi. Dalam examination tersedia option a,b,c, dan d. Bila user mengklik salah satu darinya, maka jawaban itu akan disimpan, setelah semua soal dijawab, akan muncul nilai, sesuai dengan jawaban yang benar.

Modul Practice Test, Modul practice test merupakan modul yang berfungsi untuk menguji kemapuan siswa terhadap satu sub-pokok bahasan tertentu, misalnya gerak parabola. Pada practice test tersedia option a,b,c, dan d. Bila user mengklik salah satu darinya, jawaban di ketahui saat itu juga, baik benar maupun salah. Untuk itu semua item soal terhubung dengan opsi yang disediakan dengan dua macam hasil salah / benar atau correc / wrong.

Modul Jawaban masalah, Modul ini berfungsi untuk memberikan jawaban terhadap masalah yang di ajukan pada sajian materi, dilengkapi dengan program analisis secara kuantitatif, dilengkapi dengan demo yang diperlukan. Untuk interaktivitas sistem dengan siswa digunakan button-button

Modul program Help pada Practice Test, Modul ini memuat jawaban soal pada practice test. Dapat berupa program analisis secara kuantitatif maupun berbentuk narasi, dilengkapi juga dengan demo yang diperlukan. Untuk interaktivitas sistem dengan siswa digunakan button.

\section{HASIL DAN PEMBAHASAN}

Implementasi program pembelajaran elearning berbasis ICT adalah sebagai berikut:

\section{Desain Model Program Elearning}




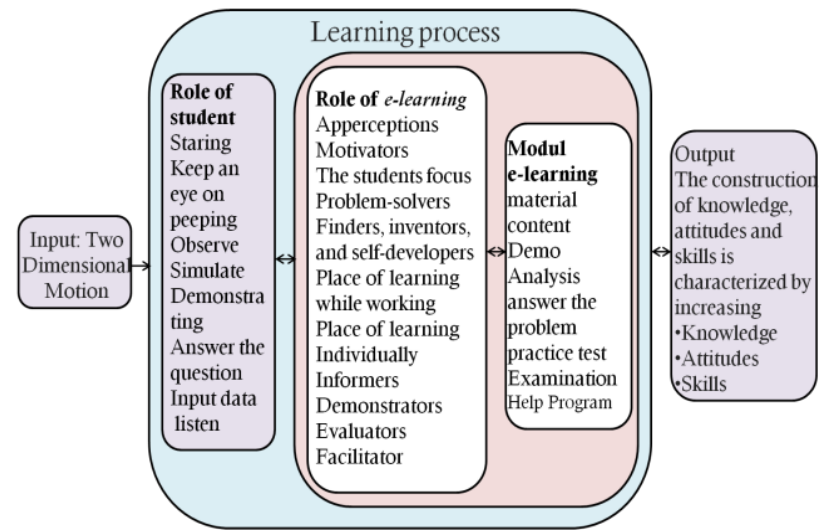

Gambar 2. Desain Model Program Elearning

\section{Modul Sajian Materi ajar}

Modul ini menampilkan materi ajar yang akan diberikan berupa narasi dan dilengkapi dengan "button" sebagai wahana interaktifitas siswa dengan program pembelajaran

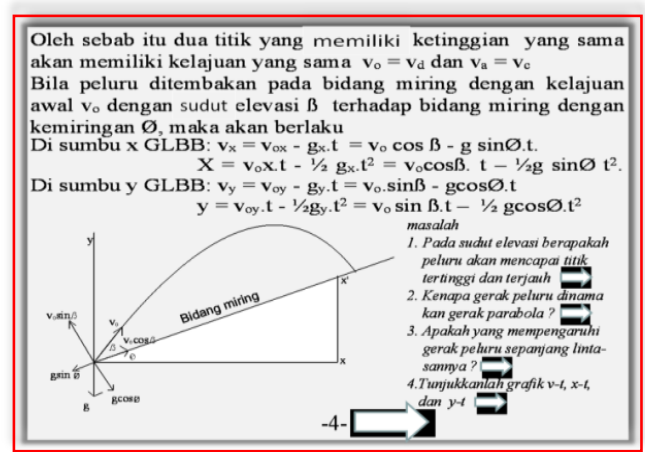

Gambar 3. Sajian Materi Program e-Learning

3. Modul demo

Demo gerak peluru dengan berbagai sudut elevasi

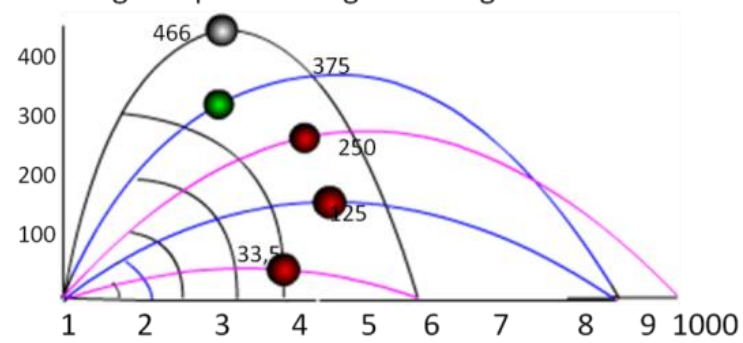

Gambar 4. Demo pada Program e-Learning

4. Modul analisis

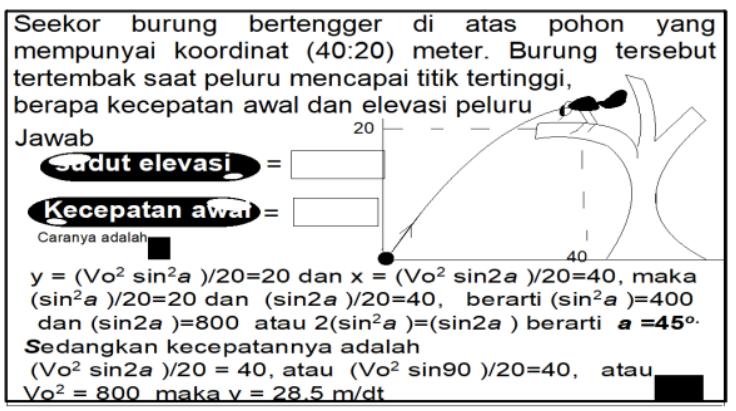

Gambar 5. Program Analitis e-Learning
5. Modul examination

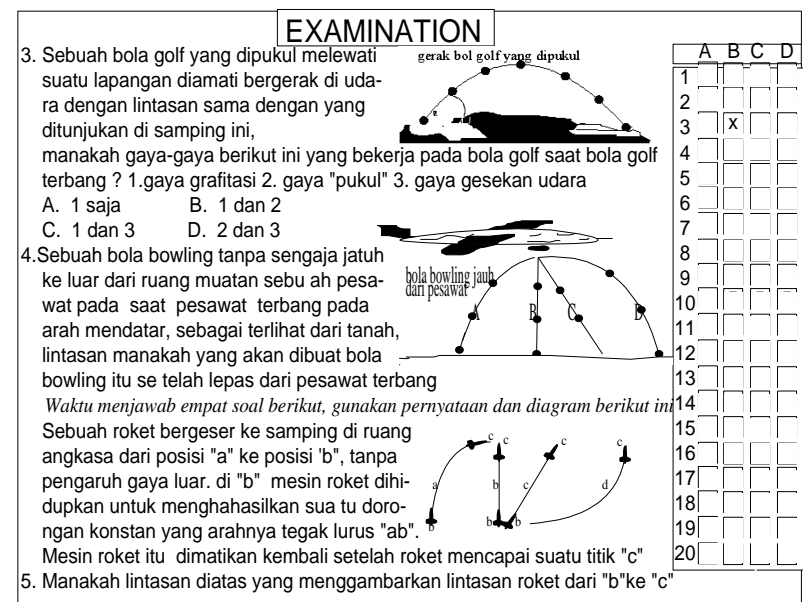

Gambar 6. Examination pada Program e-Learning

6. Modul Practice test

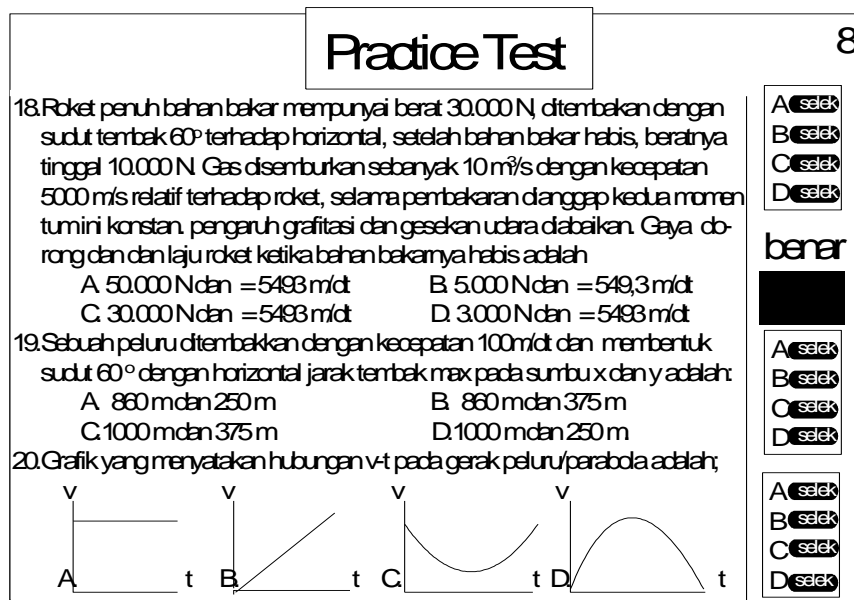

18.Janeben BCD salahyang benar adalag A sebab Gayadorong $(\mathrm{F})=$ Vrel. $. \mathrm{dM} / \mathrm{d}=5000$. $10=50.000$ Ndan Keoepatan $v-v o=-v$ rel $\ln (\mathrm{Mb} / \mathrm{M})=-\mathrm{v}$ red $\ln [1+(\mathrm{Mb}-\mathrm{MMM}) \mathrm{v}=\mathrm{v}$ rel In

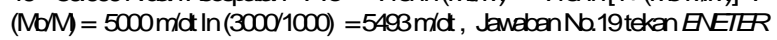

Gambar 7. Practice Test pada Program e-Learning

7. Modul Jawaban Masalah

1.Jawabannya adalah:

Tinggi (hMax.) $=($ Vo2 $\sin 2 \mathrm{a} / 2 \mathrm{~g})$, maka untuk (hMax.) nilai $\sin 2 a=\max =1$, akibatnya $a=90$, ini berarti

Peluru akan mencapai tinggi max. jika sudut elevasi 90 o Jangkauan Max.(RMax)= (Vo2 sin2a/g), maka untuk(RMax.) nilai $\sin 2 a=\max =1$, akibatnya $2 a=90, a=45$ ini berarti Peluru mencapai jangkauan max. jika sudut elevasi 450

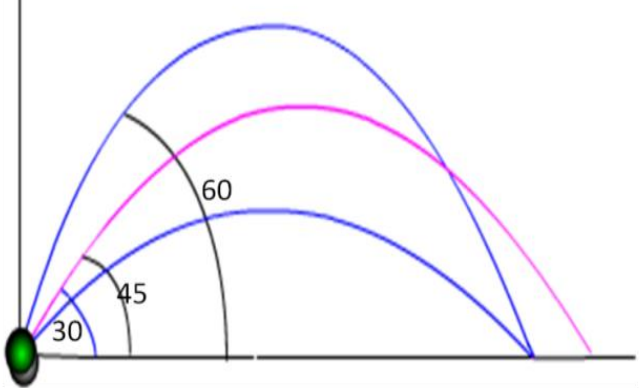

Gambar 8. Program jawaban masalah pada Program e-Learning 


\section{Modul program Help pada Practice Test}

\section{Janeben BCODsalah janebenyang bener addih (A) karenalintasan Amenujuktkangerak lun sberaturan (GB) sama dengan sebelummesin roket dhidupkan yaitu bergerak (benpindeh) dari "al" ke'b"' (horizontal ke kanan Lihat illustrasi d banehiri}

a

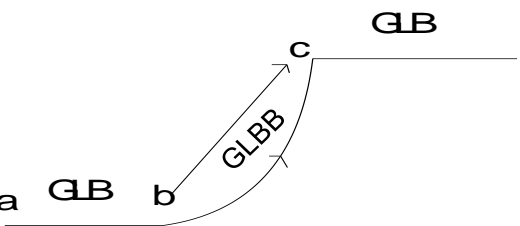

Gambar 9. Program program pada Program eLearning

Hasil penelitian memperlihatkan bahwa, Program E-learning mampu sebagai wadah Kegiatan belajar, Kebutuhan belajar, Sarana belajar dan Peran sarana belajar yang diimplemenatsikan dalam modul modul pembelajaran, Modul Sajian Materi ajar, Modul Demo, Modul Analisis, Modul Examination, Modul Practice Test, Modul Jawaban masalah, dan Modul program Help pada Practice Test.

Temuan ini sejalan dengan temuan lain yaitu, project requirement menggunakan model Product-Service System (PSS) untuk menentukan roadmap pengembangan e-learning secara utuh terlaksana dengan baik dan layak untuk diwujudkan (Risnandar, 2010). Interactive 3D elearning disukai dan sangat disukai sebagai media pembelajaran $74 \%$, meningkatkan kemampuan kognitif $83 \%$, menarik dan mudah digunakan $77 \%$, memotivasi dan menarik minat belajar $78 \%$. (Sianipar, 2010). Seiring temuan riset di atas akhir-ahkir ini ditandai oleh adanya format belajar berbentuk Cyber (e-learning) melalui komputer dan internet (Sehat Sempurna., 2012). Kelas online cenderung menjadi sukses bila didasari oleh ilmu pedagogis dan penyusuan materi ajar yang benar (Mustadji., 2011).

Aktivitas dan prestasi belajar mahasiswa pada mata kuliah analisis real berbasis web dalam bentuk e-learning meningkat, dan ketuntasan belajar mahasiswa tercapai sebesar 92,5\% (Kurniati, et al., 2014). Skor Keefektivitas elearning sebagai perencanaan (77,57\%), pembuatan materi $(75,14 \%)$, penyampaian materi (66,14\%), interaksi $(75 \%)$, evaluasi $(69,01 \%)$, dan media pembelajaran sebaesar $77,27 \%$ (Numiek, 2013). Mahasiswa JPTE PT UNM termotivasi dalam pembelajaran Instalasi Listrik 2 yang menggunakan animasi adobe flash CS3 pada kategori baik (75\%) (Hasrul, 2011). Pengembangan Pembelajaran fisika dengan multiple Representations Berbasis ICT meningkatkan penguasaan Konsep Kinematika, persepei dan motivasi yang baik (Ishafit, 2014). Pembelajaran Biologi menggunakan elearning berbasis multiple intelligences pada system gerak manusis menunjukan hasil belajar meningkat sebesar $21 \%$ dan ketuntasan belajar mencapai $100 \%$, sehingga proses pembelajaran mahasiswa menjadi efektif (Murdiyani, 2012).

E-learning sebagai media pembelajaran interaktif berbasis Teknologi Informasi diwujudkan dalam bentuk modul yang memuat konten guru yang meliputi soal, pengumuman, upload materi ajar, memriksa, dan mengumumkan hasil ujian, serta konten siswa meliputi melihat pengumuman, hasil ujian dan men-download materi ajar sangat baik digunakan sebagai media pembelajaran interaktif berbasis Teknologi Informasi, (Yazdi, M. 2012). Elearning moodle menurut pakar dan ahli media layak digunakan dengan katagori baik 3,98 dan berdasarkan uji beta termasuk katagori sangat baik dengan skor 4,15 , uji produk termasuk kategori baik dengan skor 3,90 dan efektif meningkatkan hasil belajar siswa sebesar 13,24 (Zyainuri, et al, 2012). Elearning berbantuan virtual laboratory valid untuk digunakan, terbukti dengan nilai skor para ahli untuk aspek materi sebesar 91,67\%, aspek media sebesar $96,75 \%$. Skor angket mahasiswa untuk praktikum online $81,30 \%$, untuk tahap small group $81,50 \%$, dan sangat praktis digunakan (Agustine, et al, 2014).

Penggunaan Program E-learning dalam Pembelajaran Fisika dapat mengurangi miskonsepsi siswa sebesar $71 \%$ dari $91,7 \%$ menjadi 20,7\% (Mayub A., 2017). Sejalan dengan itu ada pengaruh penggunaan program e-learning terhadap motivasi belajar siswa dalam kategori cukup termotivasi (Skor 3,52 dari kisaran skor 1-5) dan terdapat hubungan yang signifikan antara program e-learning dan motivasi belajar (Mayub A., 2015), ditemukan juga bahwa, penggunaan program e-learning dalam pembelajaran fisika dasar "Cukup berkontribusi" dengan skor 3,44 (skala 1-5). Hubungan antara program e-learning terhadap perannya dalam pembelajaran fisika dasar berada pada kategori sedang,tinggi/kuat dan sangat tinggi/kuat sebesar $91,25 \%$, sedangkan kategori rendah/lemah sebesar $8,75 \%$. Program e-learning fisika mampu bertindak sebagai penyaji bahan ajar yang dapat menarik perhatian siswa, menjelaskan materi, menunjukkan gejala fisik, percobaan virtual, menganalisis, mengajukan pertanyaan, memberikan umpan balik, memotivasi siswa, berfungsi sebagai sekolah/ kelas, serta mampu membawa siswa ke dalam lingkungan belajar yang menyenangkan dan tidak membosankan (Mayub 
A., 2018).

\section{KESIMPULAN}

Berdasarkan peneltian yang telah dilakukan ditemukan bahwa; Untuk implementasi program pembelajaran e-learning berbasis ICT dapat dilakukan dengan membuat modul modul pembelajaran yang saling terkoneksi satu sama lain. Rancangan dan implementasi Program $e$ learning memuat modul materi ajar, modul untuk demo, modul analisis, modul examination, modul practice test, modul jawaban masalah, dan modul program Help pada Practice Test. Agar terjadi interakasi edukatif antara user dengan program $e$ learning diperlukan interface berupa button. Berdasarkan uji coba program e-learning oleh user diperoleh bahwa interaktivitas usur dengan program e-learning berfungsi dengan sangat baik. Program E-learning memfasilitasi kebutuhan belajar untuk kegiatan belajar yang mencakup membaca, menatap, mengawasi, mengintip, mengamati, mendemokan, mensimulasikan, mendengarkan, menjawab pertanyaan, memasukkan data, menelusuri materi ajar, mengerjakan soal, dan mencari jawaban permasalahan.

\section{DAFTAR PUSTAKA}

Alfred J. DeGennaro. (2010). Application of Multiple Intelligence Theory to an ELearning Technology Acceptance Model, This Dissertation is brought to you for free and open access by Engaged Scholarship @ CSU, Cleveland State University.

Ayesha Perveen. (2018). Facilitating Multiple Intelligences Through Multimodal Learning Analitics, Turkish Online Journal of Distance Education-TOJDE January 2018 ISSN 1302-6488 Volume: 19 Number: 1 Article 2

Bhaskaran and P. Swaminathan. (2014). Intelligent Adaptive E-learning Model for Learning Management System, Research Journal of Applied Sciences, Engineering and Technology 7(16): 3298-3303, 2014 ISSN: 2040-7459; e-ISSN: 2040-7467, April 25, 2014, India

Budi, Brian Nurjayanti. (2012). Pengembangan Metode Pembelajaran Online Berbasis Elearning pada mata kuliah Pemrograman Teknik Komputer IPB Bogor, Jurnal Sains Terapan Edisi II Vol.2 No.1 Hal 103-113.

Christopher Pappas. (2005). Multiple Intelligences In eLearning: The Theory And Its Impact, elearning industry.

DePorter and Hernacki. (2011). Differences in
Learning Method Uusing Quantum Learning Flash Animation with Conventional Learning On The Concept of Temperature and Heat, Google Translate for Business: Translator Toolkit Website Translator Global Market Finder

Dian Kurniati, Dinawati Trapsilasiwi. (2014). Pengembangan model Pembelajaran analisis real berbasis web dalam bentuk e-learning; (C)Kadikma, Vol.5, No.3, hal 1-12.

Dwi Agustine, Ketang Wiyono, M.Muslim. (2014). Pengembangan elearning berbantuan virtual laboratory untuk mata kuliah praktikum fisika dasar II di program studi pendidikan fisika FKIP UNSRI, Jurnal Inovasi dan Pembelajaran Fisika Vol.1 No.1.

E-learning Team. (2004). Buku Panduan WebCT 4.1 Untuk Pengajar, Universiteit Utrecht dan Universitas Padjadjaran, Bandung.

FE Gouws. (2008). Journal Teaching and learning through multiple intelligences in the outcomes-based education classroom, Africa Education Review, Volume 4.

Haryono. (2012). Virtual Learning/ Virtual Classroom, Sebagai model pendidikan jarak jauh: Konsep dan penerapannya. Seminar Nasional Teknologi Pembelajaran, Balai Besar Pengembangan Teknologi Tepat Guna-LIPI.

Hasrul. (2011). Desain Media Pembelajaran Animasi berbasis Adobe Flash CS3 pada mata kuliah intalasi listrik 2, Jurnal Medtek, Vol.3 No.2 Oktober 2011.

Ishafit. (2014). Pengembangan Pembelajaran fisika dengan multiple Representations Berbasis ICT untuk meningkatkan Penguasan Konsep Kinematika, Persepei, dan motivasi Mahasiswa PGMIPA-BI, Prosideding Pertemuan Ilmiah XXVIII HFI Jateng \& $D I Y$, Yogyakarta.

Isni Murdiyani. (2012). Pembelajaran Biologi menggunakan elearning berbasis multiple intelligences pada system gerak manusis, Journal of Curriculum and Educational, Vo.1, No.1.

Kunjal Bharatkumar Mankad. (2015). The Role of Multiple Intelligence in E-Learning, IJSRD International Journal for Scientific Research \& Development $\mid$ Vol. 3, Issue 05, 2015 | ISSN (online): 2321-0613

Laela Halawi. (2010). Belajar Efektif Dengan ELearning. Faculty of Human Sciences, Waseda University and Faculty of Education, Nagasaki University, Japan.

Medeiros Vieira, Leandro and Ferasso, Marcos and 
Schröeder, Christine. (2014). Connecting Multiple Intelligences through Open and Distance Learning: Going towards a Collective Intelligence? European Journal of Open, Distance and E-Learning, Volume 17, Issue 1, Jul 2014. Available at SSRN: https://ssrn.com/ abstract $=2875482$

Mayub A. (2011). Rekayasa Program E-learning Fisika Sebagai Upaya Meningkatkan Efektivitas Pembelajaran Fisika di SMA, Disertasi S-3 Teknik Elektro UGM

Mayub A. (2015). Implementasi Virtual Classroom Sebagai Upaya Memotivasi Mahasiswa Belajar Fisika, Laporan Penelitian, Hibah Penelitian Pasca Sarjana IPA FKIP UNIB, 2015

Mayub A. (2017). Improvement of student Misconceptions of physics using the Elearning, Proceeding Bengkulu International Confrence on Science and Education (BISCE-2017) ISBN 978-602-8043-84-7

Marie, Georgianna. (2009). Virtual Classroom Instruction: Strategies for Keeping Participants Engaged, Diakses Februari 2010 dari http://www.gmariegroup.com/VILT Workshop/ASTD_TK_20.

M. Yazdi. (2012). E-learning sebagai media pembelajaran interaktif berbasis Teknologi Informasi, Jurnal Ilmiah Foristek Vol.2, No.1, Maret 2012

Miftah R.S, Rini B, Elvin Y.E. (2012). Pengembangan Media Pembelajaran IPA Terpadu Interaktif dalam bentuk moodle untuk SMP Pada Tema Hujan Asam, Jurnal Pendidkan Fisika Vol.2 No.1

Morten Brekke, Peter Henrik Hosstad. (2010). New Teaching Method-Using computer technology in physics, mathematics and compoter science, International Journal of digital Society, Volume 1, issue 1, March, p.19.
Mustadji. (2011). Pemanfaatan Multimedia Untuk Meningkatkan kualitas Pendidikan, seminar AKAL interaktif di TB.Gramedia EXSPO Surabaya

Novi Hidayati. (2010). Sistem e-learning untuk meningkatkan proses belajar-mengajar pada SMA N 10 Bandar Lampung, Jurnal Telematika Mkom Vol.2, No.2, 2010

Numiek SH. (2013). Keefektivitas e-learning sebagai media pembelajaran di SMK Telkom Sandhy Putra Purwokerto, Jurnal Pendidikan Vokasi, 3 (1) Februari 2013.

Nawaz A. (2011). Using e-learning as a tool for 'education for all' in developing states, Depart.Of Public Administration, Gomal university, Deha Ismail Khan, KPK Pakistan.

Ono W. Purbo, Antonius Aditya Hartanto. (2002). Tehnologi e-Learning", PT Elex Media Komputindo, Jakarta

Putra. D.(2009). Pendidikan Berbasis Teknologi Informasi Makalah pada Rakorda Disdikpora Bali, Bali.

Risnandar. (2010). Perancangan e-learning dengan Pendekatan Product-Service System (PSS) dan DICE Framework, Konferensi dan Temu Nasional Teknologi Informasi dan Komunikasi untuk Indonesia, Bandung.

Sehat Sempurna. (2012). Perkembanagn elearning, Jur.Teknik Komputer dan jaringan ITB-SEOMOLEC, Bandung

Sianipar DB. (2010). Desain dan Pengembangan Interactive 3 Dalam Meningkatkan Kemampuan Kognitif Siswa, Laporan Penelitian, Magister Teknik Elektro ITB, Bandung.

Zyainuri, Eko Marpanaji. (2012). Penerapan elearning moodle untuk pembelajaran siswa yang melaksanakan Prakerin, Jurnal Pendidikan Vokasi, Vol.2 No.3, 2012. 